ORIGINAL PAPER

\title{
Angioinvasion as a FACTOR FOR PREDiCTING AgGRESSIVE OUTCOME IN PRIMARY THYROID ANGIOSARCOMA: THREE CASE REPORTS AND LITERATURE REVIEW
}

\author{
Adela Nechifor-Boilă ${ }^{1,2}$, Myriam Decaussin-Petrucci ${ }^{3}$, Agota Varga-Ilyés ${ }^{4}$, Laura Chinezu ${ }^{1}$, \\ Cosmin Caraşca ${ }^{1}$, Angela Borda ${ }^{1,4}$
}

\begin{abstract}
${ }^{1}$ Department of Histology, University of Medicine and Pharmacy of Tîrgu-Mureş, Romania
${ }^{2}$ Department of Pathology, Tîrgu-Mureş County Hospital, Romania

${ }^{3}$ Department of Pathology, Centre Hospitalier Lyon Sud, Hospices Civils de Lyon, Université Lyon, France

${ }^{4}$ Department of Pathology, Tîrgu-Mureş Emergency County Hospital, Romania
\end{abstract}

\begin{abstract}
We report three primary thyroid angiosarcoma (PTA) cases revealing distinctive morphological features. A systematic literature review completed our analysis to evaluate the most important morphological factors for predicting prognosis in PTAs. Three rare PTA cases were analysed. In addition, we identified 46 previously reported PTAs with available follow-up data to compare morphological features related to prognosis between patients with a favourable versus aggressive outcome. The three PTAs displayed considerable architectural heterogeneity: case 1 presented a well circumscribed tumour, extensively necrotic, with only a few highly pleomorphic vascular proliferation; cases 2 and 3 both exhibited plump epithelioid cells forming rudimentary vascular spaces or solid sheets. Case 3 also presented angioinvasion. Cases 1 and 2 were alive and disease-free at 40 and 73 months following diagnosis, respectively, whereas case 3 died within 14 months. Other significant prognostic factors were highlighted by our review and literature data analysis: increased tumour size $(\mathrm{p}=0.042)$, extrathyroidal extension $(\mathrm{p}=0.009)$, and distant metastases at diagnosis $(\mathrm{p}=0.001)$. Although regarded as highly aggressive, PTA can also be characterised by an unusual favourable outcome. For the first time we highlight the importance of reporting angioinvasion, in cases of PTA, as a possible adverse prognostic factor.
\end{abstract}

Key words: thyroid, angiosarcoma, primary, angioinvasion, prognostic.

\section{Introduction}

Primary thyroid angiosarcoma (PTA) is a rare and highly aggressive malignant tumour, showing evidence of endothelial cell differentiation [1]. A higher incidence of PTA is reported in mountainous regions (the Alps), where it may comprise $2-10 \%$ of all thyroid malignancies [2]. However, interestingly, PTA is exceptional in non-mountainous regions, representing only $0.005 \%$ of all thyroid tumours [3]. Its preva- lence in mountainous regions mainly relates to dietary iodine deficiency and long-standing goitre because most thyroid angiosarcomas arise in multinodular goitre $[4,5]$. Although the aetiology of PTA remains unknown, recurrent intranodular haemorrhagic events and infarction phenomena in goitre are possible factors, eventually leading to malignant transformation and invasive growth of endothelial cells $[6,7]$.

According to literature data, PTAs are more frequent in women (ratio $4.5: 1$ ) and typically occur in 
elderly patients, particularly in their 70 s $[1,3]$. Generally, tumours appear as either a "cold" nodule accompanied by pain or pressure symptoms, or a painless, infiltrating mass with a tendency to increase in size $[1,8]$. In macroscopy, tumours are typically large with extensive areas of necrosis and haemorrhage [9]. Histological analysis frequently shows freely anastomosing channels, lined by atypical endothelial cells, often associated with papillary features and/or solid, undifferentiated areas $[1,6,8,9]$. The pattern of growth is nearly always invasive with prominent tumor necrosis [9].

The prognosis of PTA is generally poor, with a fatal outcome within six months, regardless of treatment [1]. However, cases of long survival have also been reported in the literature $[2,3,10,11,12,13$, 14,15 , showing that PTA can behave less aggressively. An important practical question to ask is: can a distinctive morphological feature predict patient outcome?

Here, we present three cases of PTA from two different mountainous regions (the Alps and Carpathians), which reveal several unique, distinctive morphological features, and interestingly, different outcomes. A review of clinical records and histological data in all three cases enabled the identification of clinico-pathological factors possibly related to survival. A thorough, systematic literature review of previously described morphological features, predictive for an adverse outcome in PTAs, further completed our analysis.

\section{Material and methods}

\section{Patients}

Of the three PTA cases, two were retrieved from files of the Department of Pathology, Centre Hospitalier Lyon Sud, France and one from the Department of Pathology, Tîrgu-Mureş Emergency County Hospital, Romania. Clinical history and follow-up data were available for all patients. None of the cases had previously been reported.

The Ethics Committee of the medical faculty (Tîrgu-Mures and Lyon) and the State Medical Board agreed to these investigations, and informed consent was obtained from all patients included in this study.

\section{Histopathological and immunohistochemical analysis}

The thyroidectomy specimens were all fixed in $10 \%$ buffered formaldehyde; the tumours were extensively sampled (one block per $\mathrm{cm}$ ) and further processed according to routine practice guidelines. Five-micron-thick sections were stained with haematoxylin-phloxine-saffron (HPS).

Immunohistochemistry was performed on $4-\mu \mathrm{m}$ thick sections using the labelled streptavidin-bio- tin-peroxidase complex system from a commercially available kit (VentanaiView DAB Detection Kit) on a VentanaBenchMark Ultra automated stainer (Ventana, Illkirck, France). The antibodies (clone, dilution, source) included: thyroglobulin (DAK-Tg9, 1/2000, DAKO, Glostrup, Denmark), TTF1 (8GTG3, 1/40, ZYTOMED, Berlin, Germany), AE1/AE3 (AE1/ AE2, 1/100, DAKO, Glostrup, Denmark), factor VIII (polyclonal, 1/100, DAKO, Glostrup, Denmark), CD34 (QBEnd/10, 1/30, DAKO, Glostrup, Denmark), CD31 (JC/70A, 1/20, DAKO, Glostrup, Denmark), and p53 (BP53-12, 1/20, ZYTOMED, Berlin, Germany). Pre-treatment using the antigen retrieval technique was performed for all antibodies, except for thyroglobulin and factor VIII. Appropriate positive controls ran simultaneously for all tested antibodies. In addition, structures within the examined section known to express the detected antigen also served as an internal positive control.

\section{Literature review}

A systematic and thorough search of histologically confirmed PTAs in the literature (English language) and in the PubMed database was performed using the following keywords: "angiosarcoma", "thyroid", and "primary". Several morphological features related to prognosis were compared between PTAs with a favourable outcome and those with an aggressive outcome, including our cases. Only relevant, comprehensive data regarding the relevant pathological features were included in the analysis.

\section{Statistical analysis}

Epi Info Software version 3.5.3 (CDC, Atlanta) was used for all statistical analyses, and a two-tailed p-value $<0.05$ was considered statistically significant.

\section{Results}

Table I summarises all clinico-pathological, immunohistochemical, and follow-up data for the three study cases.

\section{Clinical and follow-up data}

Case 1

The first patient, a 74-year-old woman with a three-year history of thyroid goitre, was admitted to hospital (Tîrgu-Mureş, Romania) due to rapid enlargement of the thyroid, associated with severe cervical pain and compression symptoms (swallowing disorders and dyspnoea). A neck ultrasound demonstrated a large, heterogeneous, calcified nodule in the left lobe. The patient refused a thyroid fine-needle-aspiration (FNA) biopsy. She underwent a total 
Table I. Clinicopathological, immunohistochemical, and follow-up data for the study cases

\begin{tabular}{|c|c|c|c|}
\hline & $\begin{array}{c}\text { CASE } 1 \\
\mathrm{~F}, 74 \text { YEARS OLD }\end{array}$ & $\begin{array}{c}\text { CASE } 2 \\
\text { M, } 70 \text { YEARS OLD }\end{array}$ & $\begin{array}{c}\text { CASE } 3 \\
\text { M, } 85 \text { YEARS OLD }\end{array}$ \\
\hline History & Thyroid goitre (3 years) & Thyroid goitre (19 years) & Thyroid goitre (25 years) \\
\hline Thyroid FNA biopsy & NA & Bethesda: malignant & Bethesda: malignant \\
\hline \multicolumn{4}{|l|}{ Gross features } \\
\hline Localisation & Right lobe & Isthmus & Right lobe \\
\hline Tumour size (mm) & 70 & 80 & 90 \\
\hline Macroscopy & $\begin{array}{l}\text { Well circumscribed, } \\
\text { extensively haemorrhagic, } \\
\text { and cystic with widely } \\
\text { necrotic content }\end{array}$ & $\begin{array}{c}\text { Poorly circumscribed, } \\
\text { compact, extensively } \\
\text { haemorrhagic, and necrotic }\end{array}$ & $\begin{array}{c}\text { Well circumscribed, compact, } \\
\text { extensively haemorrhagic, } \\
\text { and necrotic }\end{array}$ \\
\hline \multicolumn{4}{|l|}{ Microscopic features } \\
\hline Growth pattern & $\begin{array}{l}\text { Irregular, freely } \\
\text { anastomosing, } \\
\text { rudimentary to } \\
\text { cleft-like, and gaping } \\
\text { vascular spaces }\end{array}$ & $\begin{array}{l}\text { Solid sheets, cords, or freely } \\
\text { anastomosing irregular, } \\
\text { cleft-like vascular spaces } \\
\text { with intraluminal papillae }\end{array}$ & $\begin{array}{c}\text { Solid sheets, small } \\
\text { nests,irregular, freely } \\
\text { anastomosing to cleft-like, } \\
\text { and gaping vascular channels, } \\
\text { with intraluminal projections }\end{array}$ \\
\hline \multicolumn{4}{|l|}{ Tumor cells } \\
\hline Type & Epithelioid & Epithelioid & Epithelioid \\
\hline Pleomorphism & Severe & Severe & Severe \\
\hline Mitosis & $12 / 10 \mathrm{HPF}$ & 17/10HPH & 16/10HPF \\
\hline \multicolumn{4}{|l|}{ Tumoural stroma/Background } \\
\hline Necrosis & Present $(>90 \%)$ & Present $(>60 \%)$ & Present $(50 \%)$ \\
\hline Fibrosis & Present (peritumoural) & Present & Present \\
\hline Inflammatory infiltrate & Present (peritumoural) & Absent & Absent \\
\hline Angioinvasion & Absent & Absent & Present \\
\hline Extrathyroidal extension & Absent & Present & Present \\
\hline Lymph node involvement & $\mathrm{NA}^{\mathrm{a}}$ & $\begin{array}{c}\text { Negative } \\
\text { (0/13 lymph nodes) }\end{array}$ & $\mathrm{NA}^{\mathrm{a}}$ \\
\hline Resection margins status & Negative & Negative & Negative \\
\hline Associated pathology & Goitre & Lymphocytic thyroiditis & Goitre \\
\hline \multicolumn{4}{|l|}{ Immunohistochemical profile } \\
\hline Thyroglobulin & - & - & - \\
\hline TTF1 & - & - & - \\
\hline $\mathrm{AE} 1 / \mathrm{AE} 3$ & - & $+*$ & $+*$ \\
\hline Factor VIII & - & $+*$ & $+*$ \\
\hline $\mathrm{CD} 34$ & - & - & - \\
\hline $\mathrm{CD} 31$ & $100 \%,+++* * *$ & $100 \%,+++* * *$ & $100 \%,+++* * *$ \\
\hline P53 & $15 \%,+++* * *$ & $80 \%,+++* * *$ & $15 \%,++* * /+++* * *$ \\
\hline
\end{tabular}

Clinical treatment and outcome

\begin{tabular}{|c|c|c|c|}
\hline Surgery & TT & $\begin{array}{c}\text { TT }+ \text { central lymph node } \\
\text { dissection }\end{array}$ & TT \\
\hline Follow-up (months) & 40 & 73 & 14 \\
\hline Adjuvant therapy & None & RT & RT \\
\hline State at the last control & ANED & ANED & DOD \\
\hline
\end{tabular}

$T T$ - total thyroidectomy; ANED - alive, no evidence of disease; DOD - died of disease; $R T$ - radiotherapy; aNA - data not available

* weak positivity, **moderate positivity, ***strong positivity 
thyroidectomy but declined any adjuvant therapy (chemo- or radiotherapy). At the final clinical evaluation 40 months after surgery, she was alive with no evidence of the disease.

\section{Case 2}

The second patient, a 70-year-old man with a 19year history of thyroid goitre was admitted to hospital (Lyon, France) due to a cold thyroid nodule on scintigraphy. The FNA biopsy diagnosed a poorly differentiated thyroid carcinoma (Bethesda 6). Surgery was recommended, and he underwent a total thyroidectomy with central lymph node dissection. Subsequently, the patient received radiotherapy. The patient was alive and disease-free 73 months after the initial diagnosis.

\section{Case 3}

The third patient, an 85-year-old man, with a 25year history of thyroid goitre was admitted to hospital (Lyon, France) for progressive enlargement of his goitre related to weight loss, alongside moderate to severe compression symptoms of two years' duration (swallowing disorders, dyspnoea, hoarseness of the voice). Ultrasound examination revealed a 9-cm mass within the thyroid isthmus, with further expansion into the thyroid lobes. There was no involvement of either the trachea or oesophagus, and a computed tomographic scan revealed no distant metastases. The FNA biopsy revealed a diagnosis of undifferentiated thyroid carcinoma (Bethesda 6), which led to an immediate total thyroidectomy followed by radiotherapy. Unfortunately, the disease recurred locally, and the patient died 14 months after the initial diagnosis.

\section{Pathological data}

\section{Gross features}

In case 1 , the macroscopic examination revealed a large, encapsulated, extensively haemorrhagic and cystic nodule $70 \mathrm{~mm}$ in size in the right lobe. At cut sections extensive necrosis was noticed. Macroscopic examinations of cases 2 and 3 both revealed compact, extensively haemorrhagic, and necrotic nodules 80 and $90 \mathrm{~mm}$ in size, respectively. Both cases involved the entire right thyroid lobe and isthmus, with additional extension into the thyroid lobes.

\section{Microscopic features}

Upon microscopic examination, all three cases fulfilled the criteria for a diagnosis of epithelioid PTA. However, each case demonstrated several distinctive, unique morphological features.

Case 1 revealed a well circumscribed and cystic nodule upon first observation. However, closer examination showed that the central area of nodule consisted entirely of necrotic areas surrounded by a fibrous, thick, desmoplastic tissue, resembling a capsule. In a few areas, the periphery of the nodule disclosed a proliferation of irregular, freely anastomosed, rudimentary to cleft-like, and gaping vascular spaces (Fig. 1A). The cells lining these vascular spaces appeared large and distinctly epithelioid, with an abundant eosinophilic cytoplasm and irregular, highly pleomorphic, vesicular nuclei. The nuclei contained prominent basophilic nucleoli and frequent mitotic figures (12/10HPF). Vascular spaces lined by flattened or plump neoplastic cells were also present.

The tumour in case 2 appeared poorly circumscribed and mainly consisted of a necrotic and haemorrhagic mass ( $>60 \%$ of the tumour). Only the periphery of the nodule revealed solid tumour areas represented by sheets and disorganised cords of large, polygonal, pleomorphic tumour cells, disclosing an epithelioid appearance (Fig. 1D). A few areas showed a proliferation of irregular, rudimentary to cleft-like, and gaping vascular spaces, occasionally filled by blood cells. Pseudo-papillary features, with papillae protruding into the cleft-like spaces were also present. There was significant cyto-nuclear atypia, with a high mitotic index (17/10HPF). Some of the cells contained multiple nuclei. Haemosiderin-laden macrophages and haemosiderin-pigments appeared in the stroma surrounding the tumour cells. The tumor infiltrated the surrounding normal thyroid tissue, extending deeply into fat tissue, with extrathyroidal extension. None of the thirteen examined lymph nodes appeared to have been involved.

In the third case, the tumor developed into an adenomatous, hyperplastic thyroid nodule, consisting of undifferentiated, highly pleomorphic tumor cells lining irregular, freely anastomosing to cleft-like, and gaping vascular spaces, with intraluminal projections (Fig. 1G). Small tumor nests or solid sheets were also observed. The tumour cells appeared epithelioid, with abundant, eosinophilic cytoplasm and large, irregular, highly pleomorphic nuclei. The mitotic index was high (16 mitoses/10HPF). Significant tumour necrosis, representing approximately $50 \%$ of the tumor mass, occurred in case 3 , and one large tumor embolus was noticed adjacent to the thyroid nodule (Fig. 1G, arrow).

\section{Immunohistochemistry}

All three tumours revealed similar immunohistochemical profiles (Table I). All three cases showed strong and diffuse positive staining for CD31 (Fig. 1B, E, H). Although cases 2 and 3 stained positive for factor VIII and CK (AE1/AE3), the staining was focal and weak. All three cases showed negative staining for thyroglobulin, TTF1, and CD34. 

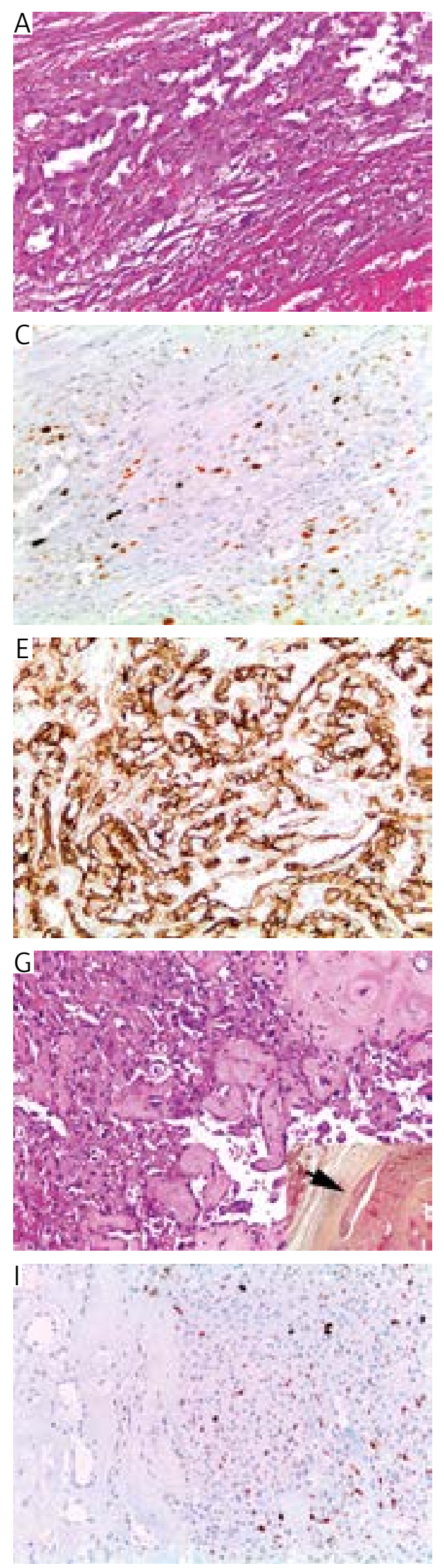
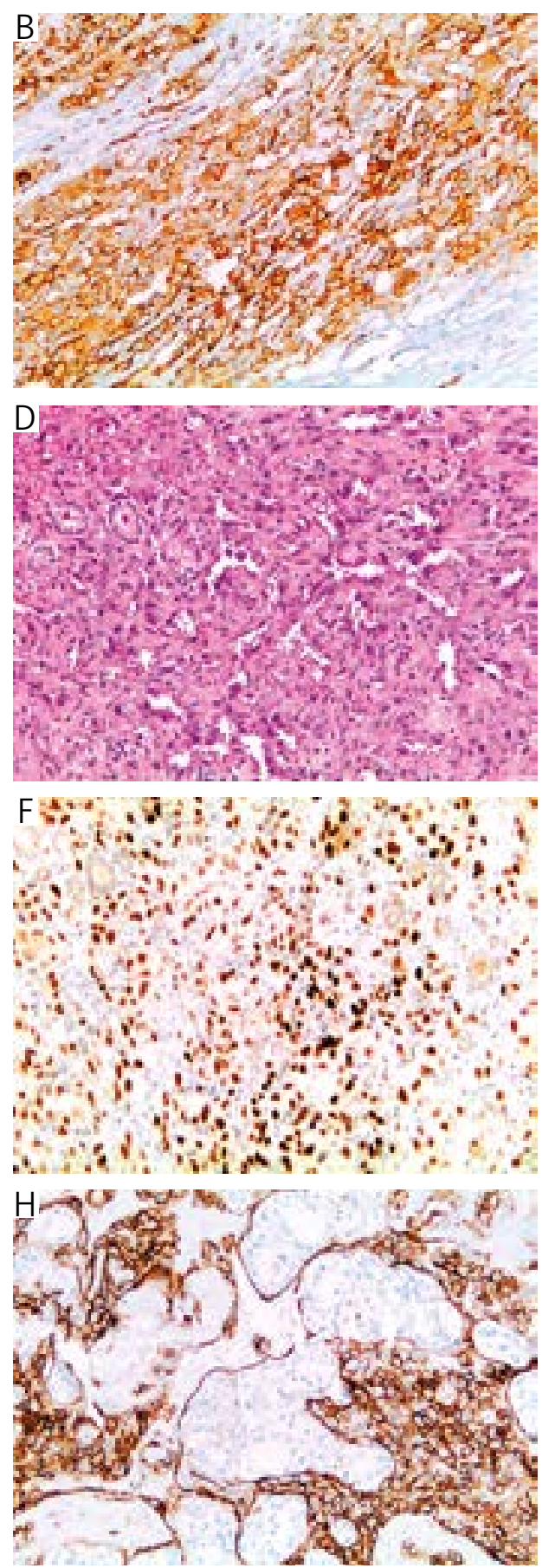

Fig. 1. Microscopic appearance of primary thyroid angiosarcoma cases (Case 1 - A, B, C; Case 2 - D, E, F; Case 3- G, H, I): Haematoxylin-phloxine-saffron (HPS): a tumour consisting of irregular, freely anastomosed, rudimentary to cleft-like, and gaping vascular spaces, lined by large, highly pleomorphic cells, with an epithelioid appearance (A); solid tumoural sheets with cleft-like spaces consisting of large, polygonal, pleomorphic tumour cells entrapping normal thyroid follicles (D); epithelioid, highly pleomorphic tumour cells lining irregular, freely anastomosing to cleft-like, and gaping vascular spaces, with intraluminal projections; a large tumour embolus was present in the thyroid parenchyma adjacent to the nodule (arrow) (G); CD31 immunostaining: strong and diffuse positivity for CD31 in all three cases $(\mathrm{B}, \mathrm{E}, \mathrm{H})$; strong/moderate $\mathrm{p} 53 \mathrm{immu}-$ noreactivity in $15 \%(\mathrm{C}), 80 \%(\mathrm{~F})$, and $15 \%(\mathrm{I})$ of the tumour cells 
Strong/moderate $\mathrm{p} 53$ immunoreactivity occurred in $80 \%, 15 \%$, and $15 \%$ of tumor cells in case 2 (Fig. 1F), case 1 (Fig. 1C), and case 3 (Fig. 1I), respectively.

\section{Literature review}

Our literature review determined only 58 previously reported, histologically confirmed PTAs $[2,3$, $4,5,8,9,10,11,12,13,14,15,16,17,18,19,20$, $21,22,23,24,25,26,27,28,29,30,31,32,33$, 34 . One case in which angiosarcoma was thought to be a metastasis in the thyroid was excluded [5]. Follow-up data were available in 46 cases $[2,3,4,5$, $8,9,10,11,12,13,14,15,16,17,18,19,20,21$, $22,23,24,25,27,31,33,34\}$. Seven cases were unsuccessfully followed-up $[2,3,19,28,29]$, one died of unrelated causes [2], and the remaining four cases had incomplete data.

The results regarding cases with available follow-up data (our cases included) are all summarised in Table II. Fifteen patients with PTA $[3,10,11,12,13$, $14,15,19]$ were alive and disease-free after a mean follow-up period of $43.47 \pm 5.9$ months, whereas six patients, [11, 27, 31, 33], although alive, showed evidence of disease after a mean follow-up period of $13.50 \pm 4.7$ months. Conversely, over half of the pa- tients $[2,3,4,5,8,16,17,18,19,20,21,22,23,24$, $25,27,34]$ died from their disease after a mean period of $5.19 \pm 1.3$ months. PTA patients with an aggressive outcome showed a significantly higher prevalence of: increased tumour size $(\mathrm{p}=0.042)$, extrathyroidal extension $(\mathrm{p}=0.009)$, and distant metastases at diagnosis $(\mathrm{p}=0.001)$, compared to those with a favourable outcome.

\section{Discussion}

Angiosarcoma, particularly its epithelioid subtype, is a rare, highly aggressive, endothelial cell malignancy, most commonly arising in deep soft tissues [35]. A variety of other primary sites, including the thyroid gland, have been reported [36]. A systematic and thorough search of the literature (English language) and PubMed database using key-words, including "angiosarcoma", "thyroid", and "primary", revealed only 58 cases of histologically confirmed PTAs $[2,3$, $4,5,8,9,10,11,12,13,14,15,16,17,18,19,20$, $21,22,23,24,25,27,31,33,34]$.

In this paper, we report three additional PTAs originating from two different mountainous regions (two from the Alps and one from the Carpathian region). Although the three cases displayed pathological cri-

Table II. Clinico-pathological features of primary thyroid angiosarcoma cases with favourable versus aggressive outcomes: data from our cases and review of the literature

\begin{tabular}{|c|c|c|c|c|c|}
\hline \multirow[t]{2}{*}{ CLINICO-PATHOLOGICAL FEATURES } & \multirow[t]{2}{*}{ Total } & \multicolumn{3}{|c|}{$\begin{array}{l}\text { STATUS AT THE LAST CLINICAL EVALUATION } \\
\text { (TOTAL, } \mathrm{N}=49 \text { CASES) }\end{array}$} & \multirow[t]{2}{*}{$\mathbf{P}^{\mathrm{D}}$} \\
\hline & & $\begin{array}{c}\text { ANED }^{A} \\
(\mathrm{~N}=15 \text { CASES })\end{array}$ & $\begin{array}{c}\text { AWD }^{\mathrm{B}} \\
(\mathrm{N}=6 \text { CASES })\end{array}$ & $\begin{array}{c}\mathrm{DOD}^{\mathrm{c}} \\
(\mathrm{N}=28 \text { CASES })\end{array}$ & \\
\hline Age, $\mathrm{n}_{\mathrm{A}}=48$ (years, mean $\left.\pm \mathrm{SD}\right)$ & $65.30 \pm 12.1$ & $62.27 \pm 9.4$ & $70.83 \pm 6.4$ & $65.85 \pm 2.7$ & 0.750 \\
\hline Gender, $\mathrm{n}_{\mathrm{A}}=48$ (female/male) & $33 / 15$ & $12 / 3$ & $3 / 3$ & $18 / 9$ & 0.724 \\
\hline $\begin{array}{l}\text { Tumour size, } \mathrm{n}_{\mathrm{A}}=35(\mathrm{~mm}, \\
\text { mean } \pm \mathrm{SD})\end{array}$ & $65.6 \pm 30.3$ & $55.36 \pm 7.47$ & $55.0 \pm 15.00$ & $74.21 \pm 7.14$ & 0.042 \\
\hline $\begin{array}{l}\text { Extrathyroidal extension, } \\
\mathrm{n}_{\mathrm{P}} / \mathrm{n}_{\mathrm{A}}\end{array}$ & $32 / 44$ & $6 / 13$ & $4 / 6$ & $22 / 25$ & 0.009 \\
\hline Multifocality, $\mathrm{n}_{\mathrm{p}} / \mathrm{n}_{\mathrm{A}}$ & $8 / 42$ & $3 / 15$ & $1 / 3$ & $4 / 24$ & 0.650 \\
\hline Nodal metastases at diagnosis, $\mathrm{n}_{\mathrm{p}} / \mathrm{n}_{\mathrm{A}}$ & $5 / 19$ & $2 / 8$ & $0 / 2$ & $3 / 9$ & 0.510 \\
\hline $\begin{array}{l}\text { Distant metastases at diagnosis, } \\
\mathrm{n}_{\mathrm{p}} / \mathrm{n}_{\mathrm{A}}\end{array}$ & $15 / 44$ & $0 / 12$ & $1 / 6$ & $14 / 26$ & 0.001 \\
\hline Positive resection margin, $\mathrm{n}_{\mathrm{p}} / \mathrm{n}_{\mathrm{A}}$ & $11 / 20$ & $0 / 6$ & $4 / 4$ & $7 / 10$ & 0.178 \\
\hline Angioinvasion, $\mathrm{n}_{\mathrm{P}} / \mathrm{n}_{\mathrm{A}}$ & $7 / 9$ & $3 / 5$ & $0 / 0$ & $4 / 4$ & 0.440 \\
\hline $\begin{array}{l}\text { Follow-up period, } \mathrm{n}_{\mathrm{A}}=49 \\
\text { (months, mean } \pm \mathrm{SD})\end{array}$ & $17.9 \pm 22.2$ & $43.47 \pm 5.9$ & $13.50 \pm 4.7$ & $5.19 \pm 1.3$ & $<0.0001$ \\
\hline \multicolumn{6}{|c|}{$\begin{array}{l}\text { "ANED - alive, no evidence of disease; } A W D-\text { alive, with disease; } D O D \text { - died of disease; } \\
n_{A}-\text { number of available data cases; } n_{P}-\text { number of positive cases } \\
\text { References: } \\
\text { a }\{3,11,12,13,14,15,19\} \\
\text { '(1 } 11,27,31,33\} \\
\text { '(2, } 3,4,5,8,16,17,18,19,20,21,22,23,24,25,27,34\} \\
\text { 'The Fisher exact test, 2-tailed values was applied; the p value was obtained by comparing the clinico-patbological characteristics of } A N E D \text { and AWD angiosarcoma } \\
\text { cases versus DOD angiosarcoma cases. }\end{array}$} \\
\hline
\end{tabular}


teria consistent with a diagnosis of epithelioid PTA (large, pleomorphic cells with epithelioid appearance and high mitotic index), each case revealed several distinctive, unique architectural features. Most of the tumour nodule in case 1 appeared necrotic $(>90 \%)$, surrounded by a fibrous, thick, desmoplastic tissue, resembling a capsule. In a few areas, the periphery of the nodule disclosed a proliferation of irregular, freely anastomosed, rudimentary to cleft-like, and gaping vascular spaces lined by large, pleomorphic cells. The second case also revealed significant necrosis, although the solid tumoural tissue, found only at the periphery of the nodule, mainly consisted of sheets and disorganised cords of polygonal, atypical tumour cells, disclosing an epithelioid appearance. The tumour in case 3 developed into an adenomatous, hyperplastic thyroid nodule and consisted of undifferentiated, highly pleomorphic cells lining irregular vascular spaces, with intraluminal projections. This considerable architectural heterogeneity in epithelioid PTAs has previously been reported [2] and possibly represents a characteristic feature of PTA [3]. This unique morphology paired with the exceptional occurrence of the disease makes the diagnosis of epithelioid PTA challenging. In our series, the clear positive staining of tumour cells for endothelial markers, such as CD31, and uniform negative staining for both thyroglobulin and TTF1, further supported the histological diagnosis of PTA.

PTA is usually regarded as an extremely aggressive neoplasm, with a dismal prognosis, similar to anaplastic carcinoma $[1,2]$. In contrast, cases of long survival have also been reported in the literature $[2,3,10,11,12,13,14,15]$. We performed a systematic review of the literature (English language) for previously reported PTAs and compared several morphological features related to prognosis between favourable and aggressive outcomes. We found a significantly higher prevalence of: increased tumour size $(p=0.042)$, extrathyroidal extension $(p=0.009)$, and distant metastasis at diagnosis $(\mathrm{p}=0.001)$ among cases with an aggressive outcome compared to those with a favourable outcome (Table II).

Advanced age, increased tumor size, extrathyroidal extension, and distant metastases at diagnosis have all previously been reported as adverse prognostic factors in PTA $[2,5,9,11]$. Among these factors, possibly the most well documented is extrathyroidal extension $[2,5,11]$, acknowledged as an aggressive outcome predicting factor for patients with PTA by the World Health Organisation (WHO) in the 2004 Classification of Thyroid Tumours [1]. Our review and literature data analysis further advocate the significant prognostic value of these morphological features.

Of our three cases, only one presented an aggressive outcome (disease-related death 14 months after diagnosis), whereas the other two patients were both alive and disease-free 40 and 73 months after the initial diagnosis. Our analysis also revealed angioinvasion as a distinct morphological feature, which differentiated the case with an aggressive outcome from those with favourable outcomes. We therefore suggest angioinvasion as a possible adverse prognostic factor in PTA. For the first time, we highlight the importance of both looking for angioinvasion in histological analysis and reporting it as a possible adverse prognostic factor in final pathological summaries. However, we were able to investigate only one case, and further studies will also be limited by the small number of previously described PTA cases with angioinvasion. Therefore, a definitive prognostic conclusion cannot be drawn. To the best of our knowledge, only two prior series have described the presence of vascular or lymphatic invasion in PTAs [3, 25], adding up to a total of only eight PTA cases with angioinvasion (including our case; Table III). All these cases presented extrathyroidal extension, three were also multifocal, two showed lymph node involvement, and two had positive resection margins. None of the eight cases showed distant metastases at diagnosis. Follow-up data were available for seven cases, four of whom died of their disease, and three were alive and disease-free at 82, 70, and 59 months after initial diagnosis.

Two of our cases followed a favourable outcome. In case 1 , we believe the presence of a thick, fibrous tissue surrounding the tumour possibly played a "protective" role, together with the absence of extrathyroidal extension. In the second case, despite the "highly malignant" morphological features, including infiltrative margins and extrathyroidal spread of the tumour, the patient was alive and disease-free over six years after the initial diagnosis. We are unaware of other possible factors to have influenced patient prognosis, particularly in this case, although the absence of distant metastases at diagnosis and rapid onset of adjuvant therapy after surgery potentially played an important role.

Overexpression of $\mathrm{p} 53$ by immunohistochemistry has previously been identified as a strong prognostic factor in several soft-tissue sarcomas [37], including angiosarcomas [38]. Italiano et al. [38] reported a significant association between $\mathrm{p} 53$ positivity and a shorter disease-free survival in patients with primary or secondary angiosarcomas (3.4 months versus 14.9 months, $\mathrm{p}=0.002$ ). On the other hand, the authors also reported discordant results between p53 immunohistochemistry and the TP53 positive mutation status detected by sequencing. Few studies have investigated the expression of $\mathrm{p} 53$ in PTAs $[2$, $3,23]$, and so far the results have revealed inconsistency. Most cases (10/13) have been reported as p53 negative and only three as positive, with no relevant 
Table III. Clinico-pathological features of eight reported cases of primary thyroid angiosarcoma with angioinvasion (including case 3)

\begin{tabular}{lllllllllll}
\hline &
\end{tabular}

NA - not available; TT - total thyroidectomy; DOD - died of disease; ANED - alive, no evidence of disease

a the TT was completed by the resection of an oesophageal implant and a small fragment from the jugular vein

correlation to patient outcome (one patient died of disease; one was alive and disease-free 70 months after the surgery, and one patient was lost to follow-up). However, the cut-off threshold for p53 positivity slightly differ among the authors, referred to as either $>20 \%$ [2] or $>10 \%$ [3] of positive tumor cells. In our study, one case showed a strong positive nuclear expression of $\mathrm{p} 53$ in $80 \%$ of tumour cells; the patient was alive and disease-free 73 months after their surgery.

To summarise, PTA remains a rare entity and a challenging diagnosis for pathologists in different parts of the world. Although generally considered to have an extremely aggressive prognosis, our cases (case 1 and 2), as well as those reported by certain authors, have demonstrated a less aggressive behaviour of PTA. Investigation into the value of different clinico-pathological factors for predicting the outcome of PTA patients remains challenging mainly due to low patient numbers and the considerable heterogeneity of these tumours. Our study and literature review further underlines the prognostic value of: increased tumour size, the presence of extrathyroidal extension, and distant metastases at diagnosis, for predicting an aggressive outcome in patients with PTAs. We also highlight the importance of reporting angioinvasion in cases of PTA, as a possible adverse prognostic factor. However, due to the limited number of PTA cas- es with angioinvasion reported in the literature, no definitive conclusion can be drawn. Therefore, further studies including larger numbers of cases with long-term follow-up data are vital going forward.

The manuscript has been revised for English by an independent scientific language editing service (AngloScribe).

The authors declare no conflict of interest.

\section{References}

1. DeLellis RA, Williams ED. Pathology of the thyroid and parathyroid. In: Pathology and Genetics of Tumors of Endocrine Organs. DeLellis RA, Lyoyd RV, Heitz PU, (eds.). IARC Press, Lyon 2004; 57-66.

2. Ryska A, Ludvíková M, Szépe P, et al. Epithelioid haemangiosarcoma of the thyroid gland. Report of six cases from a non-Alpine region. Histopathology 2004; 44: 40-46.

3. Collini P, Barisella M, Renne SL, et al. Epithelioid angiosarcoma of the thyroid gland without distant metastases at diagnosis: report of six cases with a long follow-up. Virchows Arch 2016; 469: 223-232.

4. Kaur A, Didolkar MS, Thomas A. Angiosarcoma of the thyroid: a case report with review of the literature. Endocr Pathol 2013; 24: 156-161.

5. Goh SG, Chuah KL, Goh HK, et al. Two cases of epithelioid angiosarcoma involving the thyroid and a brief review of non-Alpine epithelioid angiosarcoma of the thyroid. Arch Pathol Lab Med 2003; 127: E70-E73. 
6. Papotti M, Arrondini M, Tavaglione V, et al. Diagnostic controversies in vascular proliferations of the thyroid gland. Endocr Pathol 2008; 19: 175-183.

7. Sapino A, Papotti M, Macri L, et al. Intranodular reactive endothelial hyperplasia in adenomatous goitre. Histopathology 1995; 26: 457-462.

8. Petronella P, Scorzelli M, Luise R, et al. Primary thyroid angiosarcoma: an unusual localization. World J Surg Oncol 2012; 10: 73 .

9. Kalitova P, Plzak J, Kodet R, et al. Angiosarcoma of the thyroid. Eur Arch Otorhinolaryngol 2009; 266: 903-905.

10. Couto J, Martins RG, Santos AP, et al. Invasive thyroid angiosarcoma with a favorable outcome. Int J Endocrinol Metab 2014; 12: e15806

11. Maiorana A, Collina G, Cesinaro AM, et al. Epithelioid angiosarcoma of the thyroid. Clinicopathological analysis of seven cases from non-Alpine areas. Virchows Arch 1996; 429: 131-137.

12. Lamovec J, Zidar A, Zidanik B. Epithelioid angiosarcoma of the thyroid gland. Report of two cases. Arch Pathol Lab Med 1994; 118: 642-646.

13. Altinay S, Ozen A, Namal E, et al. Electron microscopic analysis of an angiosarcoma of the thyroid from a non-Alpine endemic goiter region: A case report and brief review of the literature. Oncol Lett 2014; 8: 2117-2121.

14. Innaro N, Succurro E, Tomaino G, et al. Nonalpine thyroid angiosarcoma in a patient with hashimoto thyroiditis. Case Rep Oncol Med 2013; 2013: 901246

15. Yoon MS, Su PH, Young WJ, et al. Primary thyroid angiosarcoma with tracheal invasion. Intern Med 2016; 55: 11651169.

16. Bayir O, Yilmazer D, Ersoy R, et al. An extremely rare case of thyroid malignancy from the non-Alpine region: Angiosarcoma. Int J Surg Case Rep 2016; 19: 92-96.

17. Binesh F, Akhavan A, Navabii H, et al. Primary angiosarcoma of the thyroid gland in an young Iranian woman. BMJ Case Rep 2011; 2011: bcr0320114042.

18. Chan YF, Ma L, Boey JH, et al. Angiosarcoma of the thyroid. An immunohistochemical and ultrastructural study of a case in a Chinese patient. Cancer 1986; 57: 2381-2388.

19. Eusebi V, Carcangiu ML, Dina R, et al. Keratin-positive epithelioid angiosarcoma of thyroid. A report of four cases. Am J Surg Pathol 1990; 14: 737-747.

20. Isa NM, James DT, Saw TH, et al. Primary angiosarcoma of the thyroid gland with recurrence diagnosed by fine needle aspiration: a case report. Diagn Cytopathol 2009; 37: 427-432.

21. Mills SE, Gaffey MJ, Watts JC, et al. Angiomatoid carcinoma and 'angiosarcoma' of the thyroid gland. A spectrum of endothelial differentiation. Am J Clin Pathol 1994; 102: 322-330.

22. Prather J, Mehrotra S. Thyroid nodule. Primary thyroid angiosarcoma. JAMA Otolaryngol Head Neck Surg 2014; 140: 469-470.

23. Rotellini M, Vezzosi V, Bianchi S. Epithelioid angiosarcoma of the thyroid: report of a case from an Italian non-alpine area and review of the literature. Endocr Pathol 2015; 26: 152-156.

24. Tanda F, Massarelli G, Bosincu L, et al. Angiosarcoma of the thyroid: a light, electron microscopic and histoimmunological study. Hum Pathol 1988; 19: 742-745.

25. Gouveia P, Silva C, Magalhães F, et al. Non-Alpine thyroid angiosarcoma. Int J Surg Case Rep 2013; 4: 524-527.

26. Astl J, Duskovà J, Limanovà Z, et al. Hemangiosarcoma of the Thyroid Gland. A case report. Neuro Endocrinol Lett 2000; 21: 213-216.

27. Cutlan RT, Greer JE, Wong FS, et al. Immunohistochemical characterization of thyroid gland angiomatoid tumors. Exp Mol Pathol 2000; 69: 159-164.

28. Kefeli M, Mete O. An unusual malignant thyroid nodule: coexistence of epithelioid angiosarcoma and follicular variant papillary thyroid carcinoma. Endocr Pathol 2014; 25: 350-352.
29. Kim NR, Ko YH, Sung CO. A case of coexistent angiosarcoma and follicular carcinoma of the thyroid. J Korean Med Sci 2003; 18: 908-913.

30. Lin O, Gerhard R, Coelho Siqueira SA, et al. Cytologic findings of epithelioid angiosarcoma of the thyroid. A case report. Acta Cytol 2002; 46: 767-771.

31. Proces S, Schroeyers P, Delos M, et al. Angiosarcoma of the thyroid and concurrent hyperthyroidism. J Endocrinol Invest 1998; 21: 67-69.

32. Del RP, Cataldo S, Sommaruga L, et al. A rare case of thyroid haemangiosarcoma. Chir Ital 2007; 59: 747-749.

33. Fulciniti F, Di MD, Bove P, et al. Fine needle aspiration of metastatic epithelioid angiosarcoma: a report of 2 cases. Acta Cytol 2008; 52: 612-618.

34. Yilmazlar T, Kirdak T, Adim S, et al. A case of hemangiosarcoma in thyroid with severe anemia due to bone marrow metastasis. Endocr J 2005; 52: 57-59.

35. Hart J, Mandavilli S. Epithelioid angiosarcoma: a brief diagnostic review and differential diagnosis. Arch Pathol Lab Med 2011; 135: 268-272.

36. Surov A, Gottschling S, Wienke A, et al. Primary thyroid sarcoma: a systematic review. Anticancer Res 2015; 35: 51855191.

37. Das P, Kotilingam D, Korchin B, et al. High prevalence of p53 exon 4 mutations in soft tissue sarcoma. Cancer 2007; 109: 2323-2333.

38. Italiano A, Chen CL, Thomas R, et al. Alterations of the p53 and $\mathrm{PIK} 3 \mathrm{CA} / \mathrm{AKT} / \mathrm{mTOR}$ pathways in angiosarcomas: a pattern distinct from other sarcomas with complex genomics. Cancer 2012; 118: 5878-5887.

\section{Address for correspondence}

\section{Myriam Decaussin-Petrucci}

Department of Pathology

Centre Hospitalier Lyon Sud

Hospices Civils de Lyon

Université Lyon 1

69495 Pierre Bénite

Lyon, France

e-mail: myriam.decaussin-petrucci@chu-lyon.fr 